\title{
Sexual Media Exposure and its Effects on the Academic Engagement of First Year College Students
}

\author{
Sarika Joann Benjamin ${ }^{1}$, Jang Juyeon ${ }^{2}$, Ruzzel Jose L. Miclat ${ }^{3}$ and Mark B. Samson ${ }^{4}$ \\ ${ }^{1,2,3}$ Student, Adventist University of the Philippines \\ ${ }^{4}$ Faculty, Adventist University of the Philippines \\ mbsamson@aup.edu.ph
}

\begin{abstract}
Hours are spent daily on various types of media, and by choice or not, exposure to sexually explicit material may occur. Although there are several studies conducted on the negative effects of sexual media exposure such as development of sexual aggression and poor academic performance there is insufficient information regarding its relationship with academic engagement. This study determined the extent of sexual media exposure, degree of academic engagement, the relationship between these aspects, as well as the best predictor of academic engagement among first year college.

The study utilized a quantitative, descriptive- correlational design. A purposive sampling technique was used to gather 101 respondents using specified criteria. Descriptive and Inferential statistics were used in the study. Specifically, the mean, standard deviation, correlation coefficient, regression analysis, $t$-test and analysis of variance (ANOVA) was used for statistical analysis.

The study showed that the extent of sexual media exposure of first year college students in terms of frequency and duration are low. The study also revealed that the students have a high degree of academic engagement of first year college students in terms of affective, behavioral, and cognitive faculties. Further, the study revealed that there is no significant relationship between sexual media exposure and student academic engagement. A weak positive relationship exists between sexual media exposure and affective academic engagement. Finally, findings showed that sex and nationality are the best predictors of student academic engagement.

There is no relationship between sexual media exposure and student academic engagement but a weak relationship is perceived in affective academic engagement. It is recommended that the study will be conducted in a larger population considering sizeable representation of the given variables. It is also suggested that the questionnaire for sexual media exposure will be more specific, including terminologies that connote actual sexual knowledge, attitude and behavior. To sustain high degree academic engagement, exposure to possibly distracting sexual media should be studied
\end{abstract}

Keywords: Sexual Media Exposure, Academic Engagement 


\section{INTRODUCTION}

In a time period and culture where sex "sells," media has become an ideal promoter, especially through the use of television and movies (Ybarra, M. L., Strasburger, V. C., \& Mitchell, K. J., 2014). Hours are spent daily on various types of media, and by choice or not, exposure to a sexually explicit material may occur. Specifically, one type of media, the Internet, provides plentiful resources and services, including other forms of media such as television series, movies, music, games and printed literature, that has eventually led lives to revolve around its usage. Ninety-three percent of American adolescents ages 12 to 17 use the Internet. Among these adolescents, $63 \%$ go online daily while, $36 \%$ go online several times a day (Lenhart, A., Purcell, K., Smith, A., \& Zickuhr, K. , 2018). Consequently, it has become a medium for an affordable and available access to sexually explicit material, and the increased accessibility to the Internet can expose youth to potential risks due to unmonitored access (Federal Bureau of Investigation, 2011 as cited by (Owens, E. W., Behun, R. J., Manning, J. C., \& Reid, R. C., 2012). The issue at the moment is the exposure to sexual content or sexually explicit material at a very young and earlier age. Bitdefender stated that $22 \%$ of online porn consumption is by children under the age of 10 (Dumitrescu, 2017). Brain development at this time is still in the process and continues until the mid-20s (Owens, E. W., Behun, R. J., Manning, J. C., \& Reid, R. C., 2012). Majority of the studies concerning sexual media exposure especially on pornography are focused on affectations on interpersonal relationships, interactions with social gathering, as well as self-percption (Chelsen, (2011), Northup, (2013) Senn, (1993)). Although there are several studies conducted on the negative effects of sexual media exposure, there is insufficient information in regards to academic engagement. Academic engagement demonstrates a student's ability to get along with teachers, be interested in various subjects' content, and have the ability to cope and function with stressors both at home and school which includes hours spent on doing homework, meeting deadlines and attending all classes regularly. Acheampong and Adjenim (2016), examined the effects of porn among 300 senior high students, thirty-one percent of them said that pornography "eats" into their studying time, while all of them said that academic performance is affected by porn consumption. The results from that study show that the more one engages in pornography, the more one's academics is affected. Due to the easy and early exposure to sexual media, the purpose of this study is to find a correlation between sexual media exposure and academic engagement among first-year college student. 


\section{LITERATURE REVIEW}

\section{Sexual Media Exposure}

In a time where sex "sells" it seems almost impossible to avoid exposure to sexually explicit material. Sexual content has a longstanding history in television and movies but has now also found a place in music, games, literature and online. The internet is a source of vast amounts of information, ideas, and entertainment. Users spend hours daily visiting various sites for research, news, entertainment, to connect with the world and much more. As users spend more and more time on the internet so does their exposure to sexually explicit material, even if it was not their intention, through advertisements. Cooper (2002), as cited in Abell, Steenbergh \& Boivin (2015), mentions that internet porn might be more addicting than other traditional forms of pornography due to its accessibility, anonymity, and affordability. For some children, pornographic advertisements may be their first exposure to sex and possibly their source of sex education (Sun, C., Bridges, A., Johnson, J. A., \& Ezzell, M. B., 2014). A curious mind may venture into the site, leading into a world of pornography and unhealthy sexual ideas and behaviors. In a study by Shashi-Kumar, et al. (2013), it explains how sexual media exposure can lead to adolescents adopting this type of behavior and thus retracting from academics.

\section{Onset}

To review the correlation between exposure to sexual content and academic engagement by adolescents, it is important to view the impact of onset of exposure. As studied by Wolak, Mitchell, and Finkelhorn (2011), as cited by Beltramini and Romito, (2015), in Northern Europe, almost all boys and between $60 \%$ and $80 \%$ of girls have been exposed to pornographic material. This study is supported by the Porn's Phenomenon, nearly half of young people are actively seeking pornography weekly or more frequently, and more than one out of four individuals between the ages of 25 and 30, first viewed pornography before hitting puberty. Johansson, T., \& Hammaren, N. (2007), cites a related study conducted by Mossige, Ainsaar, and Svedin (2007) of which both mention that, in the United States, $42 \%$ of young internet users (10-17 years old) had viewed online pornography. As cited by Brown and L'Engle, Bryant and Brown (2009)in their study revealed that exposure to sexually explicit material was almost universal by the end of high school.

Frequency

Studies have found that watching pornography singularly can lead to eventual involvement in cybersex. In a study conducted on factors contributing to cybersex use and difficulty forming intimate relationships, it was found that individuals with a high score for frequent cybersex use 
had a more difficult time in intimate relationship formation as compared to those with a lower frequency use. (Weinstein, A. M., Zolek, R., Babkin, A., Cohen, K., \& Lejoyeux, M., 2015) Sexual content is also found in print such as books and magazines. One study concluded that teens read sensual printed media to gain awareness about sex and to satisfy their curiosities. However, in a study conducted by Bernarte, Barolata and Laurete (2015), the majority of the respondents responded to reading such content only once a month for both books and magazines while $5.9 \%$ reported a frequency of every day, $7.6 \%$ for two to three times in a week and $12.5 \%$ said once a week.

Format: Audiovisual \& Printed

In a study conducted on sexual media and its relationship to sexual violence victimization, it was founded that $47 \%$ of the 1058 youth aged 14-21 years of age reported that almost all of their media consumed, depicted sexual content. Five percent reported that almost all of their visited websites depicted sexual content, $4 \%$ reported the same for games, $32 \%$ reported the same for the music they listen to and $32 \%$ reported the same for television and movies. It was reported that television, movies, and music has much more sexual content as compared to games and online. Furthermore, females held the highest exposure to sexual media in television, movies, and music while males held the highest exposure online and in games (Ybarra, M. L., Strasburger, V. C., \& Mitchell, K. J., 2014).

A study which focused on music showed that sexual references were found in $79 \%$ of $\mathrm{R} \& \mathrm{~B}$, $78 \%$ rap, $53 \%$ pop, $37 \%$ rock and $36 \%$ of country music videos. Apart from that, $40 \%-75 \%$ of all music videos contain sexual images (Zhang, et al., 2008, as cited in (Wright, C.L., \& Craske, M., 2015).

Another study revealed that $85 \%$ of films and $82 \%$ of television programs contain sexual content in which sexual talk is more often see rather than sexual activity. On average, Americans are exposed to the television for four to five hours. According to Fisher et al, 2004, as cited in Ward, Erickson, Lippman and Giaccardi, (2016), 1,276 television programs were screened for sexual content.

A study by Bleakley, Jamieson, \& Romer, 2012, as cited in Ward, Erickson, Lippman and Giaccardi (2016), screened through 855 films for either the absence or presence of five-minute segments of sexual content. Further studies which focused on printed literature showed that $75.8 \%$ of the 400 male respondents said they read sensual literature which directly or indirectly depicted sex and that they are "less exposed" to these sensual printed media (Bernarte, R. P., Bartolata, K. E., \& Laureta, C. O., 2015) 


\section{Academic Engagement}

Engagement is a term that is defined as students' quality of participation and investment in school and extracurricular activities to better their performance in academics (Alrashidi, O., Phan, H. P., \& Ngu, B. H., 2016). Academic engagement can be determined in terms of three aspects: affective, cognitive, and behavioral.

In a study conducted on 300 senior high students examining the effects of pornography, it was found that 94 respondents or $31.3 \%$ said that pornography "eats" into their studying hours. The interesting part is that all respondents agreed that academic performance is negatively affected, and none endorsed the use of pornography (Acheampong, R., \& Adjenim, Y., 2016).

In another study assessing pornography addiction with psychosocial and academic adjustment, it was found that the students experienced a high level of porn addiction and a moderate level of academic adjustment alone. Results also showed that there was a slight positive correlation between the two (Ephraim, O. C., Chinweike, O. J., \& Michael, E., 2011).

Another study assessed the relationship between exposure to violent media and sexual media and academic performance. It states that exposure to these types of media impairs memory and occupies attentional resources that are used for focus and concentration (Cetin, Y., Lull, R. B., Celikbas, M., \& Bushman, B. J. , 2015).

Sex

Exposure to sexual content in media may vary by sex. In the study conducted by (Ybarra, M. L., Strasburger, V. C., \& Mitchell, K. J., 2014), 45\% of the youth who responded that almost all or all of at least one type of media they consumed depicted sexual content were male. For specific types of media, females held the highest exposure to sexual media in television, movies, and music, while males held the highest exposure online and in games.

Bryant (2010) discloses that males not only are exposed to more pornography unintentionally as they go through activities and mingle within environments that place them at higher risk, but also will more actively look for sexually explicit material than females will. Gender-based studies on academic engagement show the propriety of female students being more invested in their academics. Based on a study conducted by Lam, et al. (2012), females are more inclined to take their education more seriously and therefore are more engaged in their academics. It also shows that compared to their male counterpart, females are perceived to have more aid from outside sources such as friends, family, and professors. 


\section{Religion}

Past studies have shown that religion is inversely related to addictions, meaning that an individual who claims to have strong religious beliefs will not have a tendency for addictive behaviors such as alcoholism, substance abuse, smoking or gambling. However, in a study, which examined the relationship between religiosity and internet pornography use among 125 male undergraduates, it was shown that the two were not inversely related. Based on the data of this study, $31 \%$ of the sample reported to have struggled with urges to view pornography during internet use. In a broader context, this would mean that one-third of all male undergraduates struggle with urges to view pornography whenever they are using the internet (Abell, J. W., Steenbergh, T. A., \& Boivin, M. J., 2015)

In another study, results show that men with an expression of stronger commitment to their religious faith had a lower tendency to use pornography for masturbation but had a greater preference for pornography over sexual intercourse. One reason may be that pornography is a mechanism for individuals to attain their sexual desire and satisfaction without engaging in sexual intercourse as a means to stay "pure.” (Sun, C., Bridges, A., Johnson, J. A., \& Ezzell, M. B., 2014).

In a Christianity Journal called Leadership, a survey was conducted among 564 church leaders regarding sexual behavior. Some of the numbers reported include: $51 \%$, of pastors, indicated that Internet pornography is a possible temptation, 43\%, admitting they have visited a pornographic site at least one time, $21 \%$, visiting more than once a year, $6 \%$, "a couple of times a month or more", and $37 \%$ of pastors said viewing pornography was a current struggle (Taylor, K., Miles, G., Ainsworth, M., 2010) Bergin, who was cited by Taylor, Miles \& Ainsworth (2010), said that in 2002, within the area of the Saddleback Community Church, among the 6,000 pastors who visited his website, 30\% admitted viewing Internet pornography in the previous 30 days. Amid the self-identified Christian expatriates, six percent approve of pornography as a way to relieve tension (Taylor, K., Miles, G., Ainsworth, M., 2010).

Some religions teach on obeying God's command to strive for perfection; such is the case for the Islamic faith. Zubairu and Sakariyau (2016) conducted a study on Muslim Malaysian students to determine if their religiosity had a positive correlation to their academic performance. The idea behind this is the higher the cumulative grade point average, the higher the religiosity. However, results from this study showed that there was a negative correlation between the cumulative grade point average and religiosity, implying that the two have no relationship to each other. 


\section{Nationality}

Some developed countries may have a higher exposure to sexual media because of modernized or secular ideas. In the Philippines, a study was conducted on 400 males college students to determine their level of exposure to sexual printed material. Results show that these males are less exposed to this type of sexual media which is in congruence with a review by the World Health Organization that Filipino youth are still conservative on matters related to sex as compared to youth from developed countries (Bernarte, R. P., Bartolata, K. E., \& Laureta, C. O., 2015). A slight positive relationship was found in a study relating pornography addiction and academic adjustment among Nigerian students. The implication is that overindulgence in pornography causes maladjustment in academics (Ephraim, O. C., Chinweike, O. J., \& Michael, E., 2011). In Malaysia, openly talking about matters related to sex, even with parents, is considered a cultural taboo. Much information on sex and sexuality is learned through television (Ahmad, F., Pawanteh, L., Rahim, S. A., Rahim, M. H., \& Mohd, R. H. , 2012) Based on a study conducted in the United States, nationality is a factor in academic engagement. Academic engagement and performance are seen to be more prevalent in Latino immigrants than those who were born in the United States. Due to their traditional background Latino immigrants, especially students tend to take less risks when it comes to academics as it is seen as an obligation to give back to their family by devoting their time to academics because it is seen as a road to success (Gonzales, N. A., Germán, M., Kim, S. Y., George, P., Fabrett, F. C., Millsap, R., \& Dumka, L. E., 2007).

\section{METHODS}

\section{Research Design}

This research is designed as a quantitative, non-experimental, descriptive- correlational study. The reason that this particular research design was chosen was for the intensive purpose of quantifying data in order to determine whether or not there is an existing correlation between the two modifying variables. This design is used to measure numerical data and gauges whether there is a particular phenomenon that exists between the variables in question (Babbie, 2010)

\section{Population and Sampling Technique}

The population targeted for this study was first-year college students of a private university, located in Cavite, of which, 101 participants were selected. Criteria included first-year college students who were 18 and 19 years old, unmarried and enrolled in the Inter-semester 2018 at that university. A purposive sampling method was used in gathering respondents. 


\section{Respondents Demographic Profile}

The demographics of the respondents show that females accounted for 67 (66.3\%) respondents while males accounted for 34 (33.7\%) totaling 101 respondents. Among them, Seventh-day Adventists account for the majority of the respondents 79 (78.2\%), while Roman Catholic has $20(19.8 \%)$, and Born Again has 2 (2\%). When nationality of the respondents are considered, the majority of the respondents are Filipino, 76 (75.2\%); USA, 6(5.9\%); Indian, 2(2\%); South Korean, 4(4\%); Indonesian, 4(4\%); Rwandese, 2(2\%); Malaysian, 2(2\%); and Others, 5(5\%).

Others account for the respondents who were the sole representative of their respective country. Lastly, sixty-two (61.4\%) of the respondents are 18 years old, 36(35.6\%) are 19 years old and $3(3 \%)$ are 20 years old.

\section{Ethical Considerations}

This study was approved by the Ethics Review Board of the institution where the study was conducted. Permission to use the Student Engagement in School Questionnaire was granted by its author. Students were informed of the purpose of the study and that participation is voluntary and may withdraw from the study at any point should they wish to do so. A written consent was obtained from the respondents.

\section{Instrumentation}

This research used a self-constructed questionnaire to measure the independent variable and an adopted questionnaire, Student Engagement in School Questionnaire, from the study, "The Student Engagement in Schools Questionnaire (SESQ) and the Teacher Engagement Report Form-New (TERF-N): Examining the Preliminary Evidence" to measure the dependent variable. A brief explanation was given to the respondents make the goal of the questionnaire clear and verbal consent will also be given by the respondents.

The respondents were told that participation is voluntary and that all information taken from them will be kept confidential. They were then asked to answer and complete the questionnaire as well as given the instruction to answer the questions honestly and to the best of their knowledge.

\section{Analysis of Data}

The mean and standard deviation was used to determine the extent of sexual media. This helped determine the students' degree of sexual media exposure in terms of duration and frequency as well as determine the students' degree of academic engagement in terms of affective, behavioral, and cognitive. Pearson $r$ as for the third question, to determine whether or not there is a significant relationship between sexual media exposure and academic engagement, the 
statistical treatment that was used was correlation. ANOVA and T-test were used to determine whether the following modifying variables such as sex, religion, and nationality cause a significant difference in students' academic engagement when considered in the equation. Lastly, to determine whether sexual media exposure or a students' profile significantly predict academic engagement, regression was used.

\section{RESULTS}

Table 1. Frequency of Exposure to Sexual Media

\begin{tabular}{lcccc}
\hline \multicolumn{1}{c}{ Media Typ } & Mean & Std. Deviation & Scaled Response & VI \\
\hline $\begin{array}{l}\text { Television } \\
\text { Programs }\end{array}$ & 2.3465 & .97402 & Seldom & Low \\
Motion Pictures & 2.1881 & 1.11097 & & \\
Music Videos & 2.3564 & 1.15399 & Seldom & Low \\
Music Lyrics & 2.6238 & 1.19876 & Seldom & Low \\
Video Games & 1.6634 & 1.03225 & Never & Very Low \\
Magazines & 1.5248 & .76934 & Never & Very Low \\
& 1.8713 & .95565 & Never & Very Low \\
& & & & Very Low
\end{tabular}

Legend: 5=Always, 4=Often, 3=Sometimes, 2=Seldom, 1=Never

Table 1 shows the respondents' frequency of sexual exposure to specific media. It also shows that the highest frequency of sexual media exposure is from song lyrics $(M=2.6238)$, followed by music videos and television programs (both respectively, $\mathrm{M}=2.3465$ ), and the lowest form of exposure was from magazines $(M=1.5248)$.

The study revealed that the respondents either were never or seldom exposed to sexual content in different media, meaning they have a very low to low exposure. Some previous studies show the same results. Bernarte, et. al., (2015), found that the majority of their respondents used books or magazines only once a month for the purpose of satisfying their curiosities and learning about sex and due to their infrequent use of such media. As for music lyrics and music videos, Turner (2011) as cited by Wright and Craske, (2015) found that sexual references were seen in $79 \%$ of R \& B, $78 \%$ rap, $53 \%$ pop, $37 \%$ rock and $36 \%$ of country music videos. Apart from that, $40 \%-75 \%$ of all music videos contain sexual images (Wright, C.L., \& Craske, M., 2015). Considering the large percentage of sexual references and images found in music videos and lyrics, it is no wonder that the respondents of this study were so frequently exposed to sexual content in these particular types of media. 
Table 2. Duration of Exposure to Sexual Media

\begin{tabular}{|c|c|c|c|c|}
\hline $\begin{array}{l}\text { Media } \\
\text { Type }\end{array}$ & Mean & $\begin{array}{c}\text { Std. } \\
\text { Deviation }\end{array}$ & $\begin{array}{r}\text { Scaled } \\
\text { Response }\end{array}$ & VI \\
\hline $\begin{array}{l}\text { Television } \\
\text { Programs }\end{array}$ & $2.930-7$ & 1.75646 & 16-30 min. & Low \\
\hline $\begin{array}{l}\text { Motion } \\
\text { Pictures }\end{array}$ & 2.6535 & 1.79686 & 16-30 min. & Low \\
\hline Music Videos & 2.2475 & 1.20338 & $16-30 \mathrm{~min}$. & Low \\
\hline Music Lyrics & 2.5545 & 1.38907 & $16-30 \mathrm{~min}$. & Low \\
\hline Video Games & 1.9307 & 1.58907 & 10-15 min. & Very Low \\
\hline Magazines & 1.5050 & .75662 & $10-15 \mathrm{~min}$ & Very Low \\
\hline Books & 2.2673 & 1.60556 & $16-30 \mathrm{~min}$. & Low \\
\hline
\end{tabular}

Table 2 shows the duration of exposure to sexual content in media. Overall, the respondents were exposed for 10 to 15 minutes of sexual content in video games and magazines and for 16 to 30 minutes for the rest of the media types. The duration of exposure of 10 to 15 minutes is reflected as "very low" exposure and 16 to 30 minutes corresponds to "low" exposure so, overall, the duration of exposure is very low to low.

Magazines were found to have the least amount of duration of exposure, as it correlates to the least amount of frequency as well. However, television programs had the highest duration of exposure corresponding to a study by Fisher et al, (2004) as cited in Ward et al (2016)of which out of over 1,000 television programs that were screened for sexual content, $82 \%$ were found to have at least one instance of sexual talk or behavior consisting of physical touching, kissing, implied sexual intercourse or actual intercourse as to which females had higher exposure according to Ybarra et al, (2014).

Table 3. Onset of First Exposure to Sexual Content

\begin{tabular}{lccc}
\hline & Age Range & Frequency & Percent \\
\hline Valid & $3-7$ & 10 & 9.9 \\
& $8-12$ & 41 & 40.6 \\
$13-17$ & 48 & 47.5 \\
$18-22$ & 2 & 2 \\
& Total & 101 & 100 \\
& & \\
\hline
\end{tabular}


A few of the respondents were exposed to sexual content as early as three years old, however, the majority were exposed between the years 13 to 17 , followed by 8 to 12 years old. Corresponding studies show similar results of youth exposed to sexual content at early ages. In the first study, Porn Phenomenon, one out of four of the respondents in that study first viewed pornography before they hit puberty. This would mean that females were first exposed to pornography around the age of 10 and males were exposed to it around 11 years old. A similar study by Brown and L'Engle, (2009) also mentioned that the average age of the first exposure to Playboy, a magazine displaying nude women, was 11 years old for males and 12 years old for females. Another alarming study conducted by Bitdefender, an online security technology company, found that under the "under 18 years old" category, $22 \%$ of porn consumption was by children under the age of 10 (Dumitrescu, 2017). This particular study shows how the internet has become such an affordable and accessible means to sexually explicit content. For some children, pornography and magazines such as Playboy may be their first exposure to sex and possibly their source of sex education (Sun, et al., 2014).

Table 4. Onset of Exposure to Sexual Content

\begin{tabular}{|c|c|c|c|c|}
\hline & Onset (I) & Onset (J) & Mean & $\begin{array}{c}\text { Sig. } \\
\text { Difference }\end{array}$ \\
\hline \multirow[t]{12}{*}{ Affective } & $3-7$ & $8-12$ & -.25835 & .534 \\
\hline & & $13-17$ & -.19808 & .720 \\
\hline & & $18-20$ & -.32038 & .868 \\
\hline & $8-12$ & $3-7$ & .25835 & .534 \\
\hline & & $13-17$ & .06027 & .954 \\
\hline & & $18-20$ & -.06473 & .998 \\
\hline & $13-17$ & $3-7$ & .19808 & .720 \\
\hline & & $8-12$ & .06027 & .954 \\
\hline & & $18-20$ & -.12500 & .989 \\
\hline & $18-20$ & $3-7$ & .32308 & .868 \\
\hline & & $8-12$ & .06473 & .998 \\
\hline & & $13-17$ & .12500 & .989 \\
\hline \multirow[t]{9}{*}{ Behavior } & $3-7$ & $8-12$ & -.46867 & .018 \\
\hline & & $13-17$ & -.40128 & .052 \\
\hline & & $18-20$ & -.75385 & .133 \\
\hline & $8-12$ & $3-7$ & .46867 & .018 \\
\hline & & $13-17$ & .06739 & .892 \\
\hline & & $18-20$ & -.28518 & .812 \\
\hline & $13-17$ & $3-7$ & .40128 & .052 \\
\hline & & $8-12$ & -.06739 & .892 \\
\hline & & $18-20$ & -.35256 & .691 \\
\hline
\end{tabular}




\begin{tabular}{|c|c|c|c|c|}
\hline & $18-20$ & $3-7$ & .75385 & .133 \\
\hline & & $8-12$ & .28518 & .812 \\
\hline & & $13-17$ & .35256 & .691 \\
\hline Cognitive & $3-7$ & $8-12$ & -.15549 & .894 \\
\hline & & $13-17$ & .10417 & .963 \\
\hline & & $18-20$ & .08333 & .998 \\
\hline & $8-12$ & $3-7$ & .15549 & .894 \\
\hline & & $13-17$ & .25965 & .210 \\
\hline & & $18-20$ & .23882 & .952 \\
\hline & $13-17$ & $3-7$ & -.10417 & .963 \\
\hline & & $8-12$ & -.25965 & .210 \\
\hline & & $18-20$ & -.02083 & 1.000 \\
\hline & $18-20$ & $3-7$ & -.08333 & .998 \\
\hline & & $8-12$ & -.23882 & .952 \\
\hline & & $13-17$ & .02083 & 1.000 \\
\hline
\end{tabular}

The mean difference is significant at the 0.05 level.

Table 4 compares the initial age of onset of exposure to the other ages of onset for each aspect of academic engagement. Under behavioral academic engagement, results show that those exposed at ages 8-12 were more academically engaged as compared to those exposed at 3-7 years old.

The study compares the initial age of onset of exposure to the other ages of onset for each aspect of academic engagement. Under behavioral academic engagement, results show that those exposed at ages 8-12 were more academically engaged as compared to those exposed at 3-7 years old. According to a study based on early exposure to media, the respondents had less attention span and were less adept at performing autonomous tasks such as self-discipline and self-investment (Pagani LS, Fitzpatrick C, Barnett TA, and Dubow E., 2010). This shows that early exposure can have a strong effect on the mental capabilities of young individuals, taking away their sense of autonomy and having them become more impulsive and dependent. Longterm effects such as regressed learning ability due to lack of attention span can be attributed to their lack of academic engagement and affect their overall academic performance.

Table 5. Degree of Academic Engagement

\begin{tabular}{lccccc}
\hline & Mean & Std. & \multicolumn{2}{c}{ Scaled } & VI \\
Affective & 4.0746 & .5396 & Agree & High & \\
Behavioral & 3.7190 & .46031 & Neutral & Moderate & Reviation \\
Cognitive & 4.1370 & .62512 & Agree & High & \\
\hline
\end{tabular}

Legend: Strongly Agree=Very High, Agree=High, Neutral=Moderate, Disagree=Low, Strongly Disagree =Very Low 
Table 5 shows the degree of academic engagement among our respondents which is broken down into three aspects: affective, behavioral, and cognitive. In terms of affective and cognitive engagement, the respondents are highly engaged, whereas for behavioral, they are only moderately engaged. The degree of academic engagement among the respondents is broken down into three aspects: affective, behavioral, and cognitive. In terms of affective and cognitive engagement, the respondents are highly engaged, whereas for behavioral, they are only moderately engaged. Acheampong and Adjenim (2016) study discloses that pornography "eats" into students' studying time and that their academic performance is affected by porn consumption. The results from that study show that the more one engages in pornography, the more one's academics is affected. The researcher of this study found out that if exposure to sexual content is low, the degree of academic engagement is higher.

\section{Table 6. Relationship of Sexual Media Exposure to Academic Engagement}

\begin{tabular}{|c|c|c|c|c|c|c|}
\hline \multirow{2}{*}{$\begin{array}{r}\text { Academic } \\
\text { Engagement }\end{array}$} & \multicolumn{3}{|c|}{ Frequency } & \multicolumn{3}{|c|}{ Duration } \\
\hline & $\mathbf{r}$ & $\mathbf{p}$ & VI & $\mathbf{r}$ & p & VI \\
\hline Affective & -.207 & .038 & Significant & -.105 & .297 & $\begin{array}{c}\text { Not } \\
\text { Significant }\end{array}$ \\
\hline Behavioral & -.143 & .154 & $\begin{array}{c}\text { Not } \\
\text { Significant }\end{array}$ & -.104 & .302 & $\begin{array}{c}\text { Not } \\
\text { Significant }\end{array}$ \\
\hline Cognitive & .100 & .320 & $\begin{array}{c}\text { Not } \\
\text { Significant }\end{array}$ & .106 & .291 & $\begin{array}{c}\text { Not } \\
\text { Significant }\end{array}$ \\
\hline
\end{tabular}

The results show that, overall, there is no significant relationship between sexual media exposure and student academic engagement. However, when the aspects of student academic engagement are dissected, a weak relationship between sexual media exposure and affective academic engagement can be seen with the p-value of .038. This study showed that, overall, there is no significant relationship between sexual media exposure and student academic engagement. However, when the aspects of student academic engagement are dissected, a weak relationship between sexual media exposure and affective academic engagement can be seen with the p-value of .038. Despite this weak relationship between the two variables, the literature shows that there is an irrefutable relationship between the two.

Based on a study by Shashi-Kumar, et. al., (2013), it concludes that because adolescents are more inclined to change their behavior based on their environmental exposure it can be implied 
that adolescents engaged in sexual acts and behavior are less focused on academics. Another study by Collins et al., (2004) as cited by Shashi-Kumar, et. al., (2013) had found that there was a positive relationship between lower grades and early initiation of sexual intercourse. In that sense, it can be said that academic engagement is impaired because of the loss of focus geared towards academics as a second-hand factor from exposure to sexual media.

Table 7. Nationality as a Factor Affecting Academic Engagement

\begin{tabular}{llcc}
\hline & & F & Sig. \\
\hline Affective & Between Groups & 2.631 & .016 \\
& Within Groups & & \\
& Total & & \\
Between Groups & 2.378 & \\
& Within Groups & & \\
Cotal & & .010 \\
& Between Groups & 2.830 & \\
& Within Groups & & \\
& Total & & \\
\hline
\end{tabular}

The results of table 7 show that nationality is a factor that affects engagement as both affective and cognitive have significant values. An example of this would be the U.S.A based study where it analyzes Latino immigrants and how they've adapted to living within the United States. Based on the study it's seen that foreign-born immigrants tended to take less risks in terms of academics, rather had higher aspirations and investments in school (Gonzales, N. A., Germán, M., Kim, S. Y., George, P., Fabrett, F. C., Millsap, R., \& Dumka, L. E., 2007). Moreover, according to a separate study because of the immigration status of these groups, it has shown that traditional youth hold stronger beliefs in the importance of education because educational success is an aspect of fulfilling their sense of obligation and gratitude towards their family (Fuligni et al., 1999). This study further ingrains the fact that nationality is a factor that affects academic as a general and could be further assumed to affect academic engagement positively.

Table 8. Sex as a Factor Affecting Academic Engagement

\begin{tabular}{lccc}
\hline & Sex & Mean & Std. Deviation \\
\hline Affective & Female & 4.1033 & .55122 \\
Behavioral & Male & 4.0181 & .51933 \\
& Female & 3.8266 & .42982 \\
Cognitive & Male & 3.5068 & .45018 \\
& Female & 4.1828 & .57921 \\
& Male & 4.0466 & .70746 \\
\hline
\end{tabular}


According to this graph, sex is a factor affecting academic engagement. Based on the behavioral portion of the questionnaire females we're more inclined to be academically engaged than their male counterparts. There could be many factors as to why females are more inclined to be academically engaged. However, in reality, the majority of the studies do not imply that one sex excels drastically than the other. This could explain why there is a weak correlation between sex and academic engagement. An example of this would be a study that states that academic engagement among females are higher than their male counterparts; The key differences between the two we're that females were perceived to receive more help from their friends, family, and professors and thus are theorized to be better academically engaged as a result (Lam, S. F., Jimerson, S., Kikas, E., Cefai, C., Veiga, F. H., Nelson, B., ... Zollneritsch, J., 2012)

Table 9. Factors Affecting Academic Engagement

\begin{tabular}{llll}
\hline & & $\mathbf{t}$ & Sig. \\
\hline Affective & Sex & -1.1 .32 & .260 \\
& Religion & -1.020 & .310 \\
Behavioral & Nationality & -1.836 & .069 \\
& Sex & -3.644 & .000 \\
& Religion & -1.500 & .069 \\
Cognitive & Nationality & -1.057 & .293 \\
& Sex & -1.628 & .107 \\
& Religion & -1.466 & .146 \\
& Nationality & -2.718 & .008 \\
\hline
\end{tabular}

Table 10 presents the factors affecting academic engagement. Among the following variables such as sex, religion, and nationality, the results show that none of the variables are predictors of affective academic engagement. The results also show that sex is a predictor of behavioral academic engagement while nationality is a predictor of cognitive academic engagement.

The study revealed that among the following variables which are sex, religion, and nationality, the results show that none of the variables are predictors of affective academic engagement. Although this may be true for the variables for affective academic engagement, the contrary could be said for behavioral and cognitive. Behavioral is affected based on the variable sex as it can be seen that academic engagement is higher amongst the female respondents, this can be attributed how females are more engaged in the behavioral dimension of student engagement, more than their male counterparts (Lam, S. F., Jimerson, S., Kikas, E., Cefai, C., Veiga, F. H., Nelson, B., ... Zollneritsch, J., 2012). They further reiterate that boys are less motivated than 
girls and spend less time doing homework and that boys have lower expectations of themselves and are less enthusiastic about continuing their studies. The study also concluded that girls are more engaged in the cognitive dimension of student engagement. Girls are more likely than boys to plan, monitor, and regulate their cognitions and study activities.

Furthermore, nationality as a cognitive factor affecting academic engagement can also be observed. However, based on the study, due to the limitations in the diversity of the respondents, the results showed that Filipinos are drastically more engaged than any of the other nationalities that were a part of the sample. Of all nationalities reviewed in the study, more than half of the population was comprised of Filipinos resulting in $76.5 \%$. This fact contributes as a possible factor in determining the result of this specific test. This certain nationality weighed higher than the rest of the nationalities combined thus, naturally resulting in the fact that nationality is a factor that affects cognitive academic engagement. Nevertheless, in line with the result, a study conducted in the United States showed that nationality is a factor in academic engagement. Academic engagement and performance are seen to be more prevalent in Latino immigrants than those who were born in the United States. Due to their traditional background. Latino immigrants, especially students, tend to take less risks when it comes to academics as it is seen as an obligation to give back to their family by devoting their time to academics because it is seen as a road to success (Gonzales, N. A., Germán, M., Kim, S. Y., George, P., Fabrett, F. C., Millsap, R., \& Dumka, L. E., 2007).

\section{DISCUSSION}

\section{Conclusion}

The aim of the study was to determine the relationship between the exposure to sexual media and the academic engagement among first-year college students. The study revealed that majority of the respondents had very low to low exposure to sexual media content in terms of frequency and duration. Results also showed that those who were exposed earlier had a lower behavioral academic engagement. The study also revealed that the degree of affective academic engagement of the respondents was affected when the frequency of sexual media exposure was considered. Therefore, there is a weak relationship between sexual media exposure and academic engagement. Furthermore, it showed that there is no significant difference in one's academic engagement when religion is considered. However, when nationality and sex are considered, there is a significant difference in all three aspects of academic engagement. Finally, the findings show that sex and nationality are best predictors of academic engagement. 
Though the study did not reflect quantifiable relationship between sexual media exposure and student academic engagement, a weak relationship is seen in affective academic engagement. This should be considered as a basis for further study. Further limitations of this study include a small population size, unequal distribution of respondents within the given variables such as sex, nationality, and religion, and a broad formulation of the sexual media exposure questionnaire. It is strongly recommended that the study will be conducted in a larger population sample considering sizeable representation on the given variables. It is also suggested that the entries in the questionnaire for sexual media exposure will be more direct and specific including terminologies that connote actual sexual knowledge, attitude and behavior. It is believed that when this is cogitated, a more substantial result may arise

\section{REFERENCES}

Ybarra, M. L., Strasburger, V. C., \& Mitchell, K. J. (2014). Sexual media exposure, sexual behavior, and sexual violence victimization in adolescence. Clinical Pediatrics, 12391247.

Lenhart, A., Purcell, K., Smith, A., \& Zickuhr, K. . (2018). Internet and Technology. Retrieved from Pew Research Center: http://www.pewinternet.org/files/oldmedia/ Files/Reports/2010/PIP_Social_Medi_and_Young_Adults_Report

Owens, E. W., Behun, R. J., Manning, J. C., \& Reid, R. C. (2012). The impact of internet pornography on adolescents: A review of the research. . Sexual Addiction \& Compulsivity, 100.

Dumitrescu, G. (2017). Unplugging pornography-equipping parents and teachers to fight the drug, and helping students stay pure. 5th International Scholars Conference Journal.

Chelsen, P. O. (2011, December). Retrieved from Loyola eCommons: http://ecommons. luc.edu/cgi/viewcontent.cgi?article=1149\&context=luc_diss\& pDevExLB.1,5486.

Northup, T. (2013). Examining the Relationship Between Media Use and Aggression, Sexuality, and Body Image. Journal of Applied Research on Children: Informing Policy for Children at Risk, 15.

Senn, C. Y. (1993). Women's Multiple Perspectives and Experiences with Pornography. Psychology of Women Quarterly.

Abell, J. W., Steenbergh, T. A., \& Boivin, M. J. (2015). Cyberporn use in the context of religiosity. Journal of Psychology and Theology, 34(2), 165-171.

Acheampong, R., \& Adjenim, Y. . (2016). Effects of pornography on senior high school students. International Journal of Management and Scientific Research. 
Sun, C., Bridges, A., Johnson, J. A., \& Ezzell, M. B. (2014). Pornography and the male sexual script: An analysis of consumption and sexual relations. Archives of Sexual Behavior, 45 (4), 983-994.

Shashi-Kumar, R., Das, R. C., Prabhu, H. R. A., Bhat, P. S., Prakash, J., Seema, P., \& Basannar, D. R. . (2013). Interaction of media, sexual activity and academic achievement in adolescents. . Medical Journal, Armed Forces India, 69(2), 138-143.

Romito, P., \& Beltramini, L. (2015). Factors associated with exposure to violent and degrading pornography among high school students. The Journal of School Nursing, 31 (4), 280290.

Johansson, T., \& Hammaren, N. . (2007). Hegemonic masculinity and pornography: people's attitudes toward and relations to pornography. Journal of Men's Studies , 57-70.

Brown, J. D., \& L'Engle, K. L. (2009). X-Rated: Sexual Attitudes and Behaviors Associated With U.S. Early Adolescents' Exposure to Sexually Explicit Media. Communication Research 36 (1), 129-151.

Weinstein, A. M., Zolek, R., Babkin, A., Cohen, K., \& Lejoyeux, M. (2015). Factors predicting cybersex use and difficulties in forming ntimate relationships among male and female users of cybersex. Frontiers in Psychiatry, 6, 54.

Bernarte, R. P., Bartolata, K. E., \& Laureta, C. O. (2015). Sex and print media: The level of exposure of Filipino youth to sensual print media in relation to their attitude toward sex. Canadian Scientific Journal.

Ybarra, M. L., Strasburger, V. C., \& Mitchell, K. J. (2014). (2014). Sexual media exposure, sexual behavior, and sexual violence victimization in adolescence. Clinical Pediatrics, 53(13), 1239-1247.

Wright, C.L., \& Craske, M. (2015). Music's influence on risky sexual behaviors: examining the cultivation theory. Media psychology Review. Vol. 9(1).

Ward, L. M., Erickson, S. E., Lippman, J. R., \& Giaccardi, S. (2016). Sexual media content and effects. Oxford Research Encyclopedia of Communication.

Alrashidi, O., Phan, H. P., \& Ngu, B. H. (2016). Academic engagement: an overview of its definitions, dimensions, and major conceptualizations. International Educational Studies, 9(12), 41-52.

Ephraim, O. C., Chinweike, O. J., \& Michael, E. (2011). Pornography addiction as correlate of psychosocial and academic adjustment of students in universities in Lagos State. $U S$ China Education Review, 907-920.

Cetin, Y., Lull, R. B., Celikbas, M., \& Bushman, B. J. . (2015). Exposure to violent and sexual media content undermines school performance in youth. Advances in Pediatric Research, 2(6), 1-7. 
Bryant, C. (2010). Adolescence, pornography and harm. Youth Studies Australia, 18-26.

Lam, S. F., Jimerson, S., Kikas, E., Cefai, C., Veiga, F. H., Nelson, B., ... Zollneritsch, J. (2012). Do girls and boys perceive themselves as equally engaged in school? The results of an international study from 12 countries. . Journal of School Psychology, 7794.

Sun, C., Bridges, A., Johnson, J. A., \& Ezzell, M. B. (2014). Pornography and the male sexual script: An analysis of consumption and sexual relations . Archives of Sexual Behavior, 45(4), 983-994.

Taylor, K., Miles, G., Ainsworth, M. (2010). Survey of expatriate Christian men living in Cambodia regarding views and practices of pornography, erotic massage, and prostitution. Abilene Christian University Press.

Zubairu, U. M., \& Sakariyau, O. B. . (2016). The relationship between religiosity and academic performance amongst accounting students. International Journal of Evaluation and Research in Education, 5 (2), 165-173.

Ahmad, F., Pawanteh, L., Rahim, S. A., Rahim, M. H., \& Mohd, R. H. . (2012). Representation of sexuality on television: values and attitudes of young Malaysian. Asian Social Science, 8 (7), 77-85.

Gonzales, N. A., Germán, M., Kim, S. Y., George, P., Fabrett, F. C., Millsap, R., \& Dumka, L. E. (2007). Mexican American adolescents' cultural orientation, externalizing behavior and academic Engagement: The role of traditional cultural values. American Journal of Community Psycholigy, 151-164.

Babbie, E. R. (2010). The Practice of Social Research. 12th ed. . Belmont, CA : : Wadsworth Cengage.

Pagani LS, Fitzpatrick C, Barnett TA, and Dubow E. (2010). Prospective associations between early childhood television exposure and academic, psychosocial, and physical wellbeing by middle childhood. Arch Pediatr Adolesc Med., 425-431. 